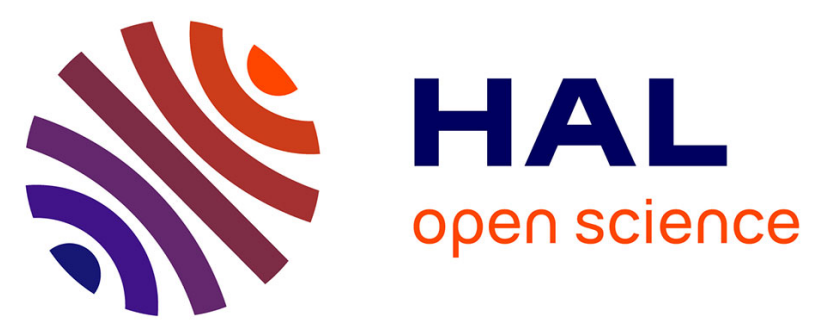

\title{
GTS-21 inhibits pro-inflammatory cytokine release independent of the Toll-like receptor stimulated via a transcriptional mechanism involving JAK2 activation
}

Matthijs Kox, Jeroen F. van Velzen, Jan C. Pompe, Cornelia W. Hoedemaekers, Johannes G. van Der Hoeven, Peter Pickkers

\section{To cite this version:}

Matthijs Kox, Jeroen F. van Velzen, Jan C. Pompe, Cornelia W. Hoedemaekers, Johannes G. van Der Hoeven, et al.. GTS-21 inhibits pro-inflammatory cytokine release independent of the Toll-like receptor stimulated via a transcriptional mechanism involving JAK2 activation. Biochemical Pharmacology, 2009, 78 (7), pp.863. 10.1016/j.bcp.2009.06.096 . hal-00509509

\section{HAL Id: hal-00509509 \\ https://hal.science/hal-00509509}

Submitted on 13 Aug 2010

HAL is a multi-disciplinary open access archive for the deposit and dissemination of scientific research documents, whether they are published or not. The documents may come from teaching and research institutions in France or abroad, or from public or private research centers.
L'archive ouverte pluridisciplinaire HAL, est destinée au dépôt et à la diffusion de documents scientifiques de niveau recherche, publiés ou non, émanant des établissements d'enseignement et de recherche français ou étrangers, des laboratoires publics ou privés. 


\section{Accepted Manuscript}

Title: GTS-21 inhibits pro-inflammatory cytokine release independent of the Toll-like receptor stimulated via a transcriptional mechanism involving JAK2 activation

Authors: Matthijs Kox, Jeroen F. van Velzen, Jan C. Pompe, Cornelia W. Hoedemaekers, Johannes G. van der Hoeven,

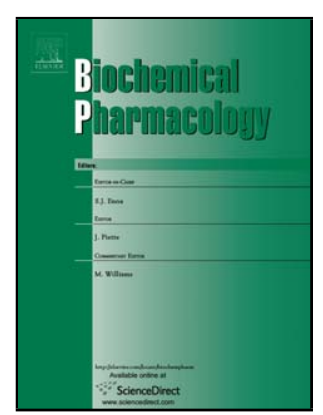
Peter Pickkers

PII:

S0006-2952(09)00567-X

DOI: doi:10.1016/j.bcp.2009.06.096

Reference: BCP 10244

To appear in: $\quad B C P$

Received date: 22-4-2009

Revised date: 12-6-2009

Accepted date: $\quad$ 23-6-2009

Please cite this article as: Kox M, van Velzen JF, Pompe JC, Hoedemaekers CW, van der Hoeven JG, Pickkers P, GTS-21 inhibits pro-inflammatory cytokine release independent of the Toll-like receptor stimulated via a transcriptional mechanism involving JAK2 activation, Biochemical Pharmacology (2008), doi:10.1016/j.bcp.2009.06.096

This is a PDF file of an unedited manuscript that has been accepted for publication. As a service to our customers we are providing this early version of the manuscript. The manuscript will undergo copyediting, typesetting, and review of the resulting proof before it is published in its final form. Please note that during the production process errors may be discovered which could affect the content, and all legal disclaimers that apply to the journal pertain. 
GTS-21 inhibits pro-inflammatory cytokine release independent of the Toll-like receptor stimulated via a transcriptional mechanism involving JAK2 activation.

Matthijs Kox ${ }^{\mathrm{a}}$, Jeroen F. van Velzen ${ }^{\mathrm{b}}$, Jan C. Pompe ${ }^{\mathrm{a}}$, Cornelia W. Hoedemaekers ${ }^{\mathrm{a}}$, Johannes G. van der Hoeven ${ }^{\mathrm{a}}$, Peter Pickkers ${ }^{\mathrm{a}}$

${ }^{a}$ Department of Intensive Care Medicine, Radboud University Nijmegen Medical Centre, Nijmegen, The Netherlands

${ }^{\mathrm{b}}$ Department of Hematology, Radboud University Nijmegen Medical Centre, Nijmegen, The Netherlands

Corresponding author: $\mathrm{P}$. Pickkers, $\mathrm{MD}, \mathrm{PhD}$

Department of Intensive Care Medicine, internal mail 632

Radboud University Nijmegen Medical Centre

PO box 9101, 6500 HB, Nijmegen, The Netherlands

Tel.: +31-24-3617273, Fax: +31-24-3541612

E-Mail:p.pickkers@ic.umcn.nl 
Abstract

The vagus nerve can limit inflammation via the $\alpha 7$ nicotinic acetylcholine receptor ( $\alpha 7 \mathrm{nAChR})$. Selective pharmacological stimulation of the $\alpha 7 \mathrm{nAChR}$ may have therapeutic potential for the treatment of inflammatory conditions. We determined the anti-inflammatory potential of GTS-21, an $\alpha 7 \mathrm{nAChR}$-selective partial agonist, on primary human leukocytes and compared it with nicotine, the $\mathrm{nAChR}$ agonist widely used for research into the anti-inflammatory effects of $\alpha 7 \mathrm{nAChR}$ stimulation. Furthermore, we investigated whether the effects of both nicotinic agonists were restricted to specific Toll-like receptors (TLRs) stimulated and explored the mechanism behind the anti-inflammatory effect of GTS-21.

GTS-21 and nicotine inhibited the release of pro-inflammatory cytokines in peripheral blood mononuclear cells (PBMCs), monocytes and whole blood independent of the TLR stimulated, with higher potency/efficacy for GTS-21 compared to nicotine. The antiinflammatory cytokine IL-10 was relatively unaffected by both nicotinic agonists. The effects of GTS-21 and nicotine could not be reversed by nAChR antagonists, while the JAK2 inhibitor AG490 abolished the anti-inflammatory effects. GTS-21 downregulated monocyte cell-surface expression of TLR2, TLR4 and CD14. qPCR analysis demonstrated that the anti-inflammatory effect of GTS-2 1 is mediated at the transcriptional level and involves JAK2-STAT3 activation. In conclusion, GTS-21 has a profound anti-inflammatory effect in human leukocytes and that GTS-21 is more potent/efficacious than nicotine. The absence of a blocking effect of nAChR antagonists in human leukocytes might indicate different pharmacological 
1

2

properties of the $\alpha 7 \mathrm{nAChR}$ in human leukocytes compared to other cell types. GTS-21

may be promising from a therapeutic perspective because of its suitability for human use.

Key words: inflammation, cholinergic anti-inflammatory pathway, nicotine, monocytes, peripheral blood mononuclear cells, $\alpha 7$ nicotinic acetylcholine receptor 


\section{Introduction}

In the past few years, a novel link between the vagus nerve and the inflammatory responses has been established. In addition to "sensing" focal inflammation in the periphery and relaying it to the brain via afferent fibers $[1,2,3]$, recent work has demonstrated that the efferent vagus nerve can modulate the inflammatory response in a reflex-like fashion, termed "the cholinergic anti-inflammatory pathway" [4]. It has become clear that the $\alpha 7$ nicotinic acetylcholine receptor ( $\alpha 7 \mathrm{nAChR})$, expressed in various cell types including human leukocytes [5], is an essential regulator of this antiinflammatory effect of the vagus nerve [6]. Consequently, more specific agonists of this receptor were identified or developed and used in various studies $[7,8,9]$. To date, one of the most effective $\alpha 7$-selective partial agonists for modulating inflammatory responses is 3-(2,4-dimethoxybenzylidene)-anabaseine (GTS-21) which has proven to be effective in attenuating the immune response and improving outcome in animal models of pancreatitis [9], endotoxemia [8,7], sepsis [7], acute lung injury [10,11] and ischemiareperfusion injury [12]. However, its anti-inflammatory potential in human inflammatory cells has never been evaluated. This is of particular interest because GTS-21, which has been primarily developed for the treatment of Alzheimer's disease, has been administered to human volunteers and patients and is well tolerated without clinically significant safety findings [13]. Therefore, GTS-21 may have therapeutic potential for the treatment of inflammatory conditions and is preferred above nicotine which lacks pharmacologic specificity and has toxic side effects and the potential to produce physical dependence (addiction). Although comparisons between GTS-21 and non-selective nAChR agonists 
have been reported at $\alpha 7 \mathrm{nAChR}$ receptor activation level in electrophysiological studies using heterologous expression in Xenopus laevis oocytes $[14,15]$, the immunomodulating effects of selective and non-selective agonists of the $\alpha 7 \mathrm{nAChR}$ have not been compared. Furthermore, in vitro studies investigating the cholinergic anti-inflammatory pathway almost exclusively used the principal Toll-like receptor 4 (TLR4) agonist LPS as a trigger for inflammation. It is unknown whether the cholinergic anti-inflammatory pathway is restricted to certain TLRs stimulated or is a general mechanism not constrained to a specific stimulus.

Finally, the mechanism by which $\alpha 7 \mathrm{nAChR}$ stimulation attenuates pro-inflammatory cytokine production has not been fully elucidated and sparcely studied in human cells. A role for the JAK2-STAT3 pathway $[16,17,18,19]$ as well as suppression of NFKB transcriptional activity $[20,21]$ is implied. However, the cholinergic anti-inflammatory pathway is believed to be regulated at a post-transcriptional level $[4,16]$. Mechanistic studies regarding the anti-inflammatory effect of GTS-21 are limited to one study reporting decreased NFkB activity in a murine cell line [7].

In this study, we investigated for the first time the anti-inflammatory potential of GTS-21 on primary human leukocytes and compared it with nicotine. Furthermore, we investigated whether the effects of both nicotinic agonists were restricted to specific TLRs stimulated and whether they affected cell-surface expression of receptors involved in the innate immune response. Finally, we studied whether the anti-inflammatory effects of GTS-21 and nicotine are regulated at the transcriptional level and determined the involvement of the JAK-STAT signal transduction pathway. 
2. Methods

\title{
2.1 General reagents
}

RPMI culture medium (RPMI 1640 Dutch modification, ICN Biomedicals; Costa Mesa, CA, USA) was supplemented with gentamicin $10 \mu \mathrm{g} / \mathrm{mL}$, L-glutamine $10 \mathrm{mM}$ and pyruvate $10 \mathrm{mM}$. GTS-21 was obtained from the University of Florida (a kind gift of Prof. Dr. Roger L. Papke) and from Comentis inc. (South San Francisco, CA, USA). No differences in potency/efficacy between GTS-21 from the University of Florida and from Comentis inc. were observed (data not shown). Nicotine (liquid, naturally occurring isomer), mecamylamine, $\alpha$-bungarotoxin, methyllycaconitine (MLA), tyrphostin AG490, d-tubocurarine and Escherichia coli lipopolysaccharide (LPS, serotype O55:B5) were obtained from Sigma-Aldrich (St Louis, MO, USA). LPS was further purified as described previously [22]. LPS concentration was $1 \mathrm{ng} / \mathrm{mL}$ in all experiments. Pam3Cys was purchased from EMC Micro-collections (Tübingen, Germany). Flagellin and polyI:C were obtained from InvivoGen (San Diego, CA, USA). All stimuli except AG490, which was dissolved in ethanol, were dissolved in RPMI.

\subsection{Peripheral blood mononuclear cells, monocyte and whole blood stimulation}

\author{
After obtaining informed consent venous blood was drawn from the cubital vein of \\ healthy non-smoking male volunteers into EDTA or lithium heparin tubes (Vacutainer \\ System, BD Biosciences, Plymouth, UK). All volunteers refrained from caffeine-
}


containing beverages/food for at least 12 hours before blood collection. Peripheral blood mononuclear cells (PBMCs) were isolated from EDTA anticoagulated blood by density gradient centrifugation over Ficoll-Hypaque (Amersham Biosciences, Uppsala, Sweden), washed three times in ice-cold sterile phosphate-buffered saline (B Braun Melsungen AG, Melsungen, Germany), and resuspended in RPMI 1640 culture medium supplemented with $10 \%$ autologous serum obtained by centrifugation $(6000 \mathrm{rpm}, 10 \mathrm{~min})$ of lithium-heparin anticoagulated blood. Cells were counted in a Bürker hemocytometer and viability was assessed using trypan blue (viability was $>95 \%$ ). The number of cells was adjusted to 2.5 x $10^{6} / \mathrm{mL}$ and $5 \times 10^{5}$ cells per well $(200 \mu \mathrm{L})$ were seeded in duplicate in 96-well flat bottom plates (Greiner, Alphen a/d Rijn, The Netherlands) and stimulated for 22 hours $\left(37{ }^{\circ} \mathrm{C}, 95 \% \mathrm{O}_{2}, 5 \% \mathrm{CO}_{2}\right)$ with various compounds. Incubation with RPMI alone served as a negative control. Nicotine or GTS-21 were added 30 minutes before TLR agonists. Nicotinic antagonists or the JAK2 inhibitor AG-490 were added 30 minutes before nicotine or GTS-21.

Primary monocytes were obtained from PBMCs using magnetic bead negative depletion (Monocyte Isolation kit II and LS columns, Miltenyi Biotec, Utrecht, The Netherlands). This procedure yields untouched monocytes suitable for short-term stimulation experiments where magnetic beads attached to cell surface epitopes are unwanted. Monocyte purity was evaluated using flow cytometry and was $85-90 \% .1$ x $10^{5}$ cells per well $(200 \mu \mathrm{L})$ in duplicate were stimulated in the presence of $10 \%$ autologous serum for 22 hours as described above.

After stimulation, $\mathrm{PBMC} /$ monocyte well plates were centrifuged $(1700 \mathrm{rpm}, 8 \mathrm{~min})$ and supernatants were stored at $-80{ }^{\circ} \mathrm{C}$ until assayed. 
For whole blood stimulation experiments, venous blood was drawn into $2 \mathrm{~mL}$ lithiumheparin containing vacutainers (Vacutainer System, BD Biosciences). Whole blood was diluted 1:5 in RPMI and stimulated for 24 hours as described above. After stimulation, whole blood cultures were centrifuged (14000 rpm, $5 \mathrm{~min})$ after which supernatants were stored at $-80{ }^{\circ} \mathrm{C}$ until assayed.

\subsection{Cytokine measurements}

Cytokines in supernatants of whole blood cultures were determined using a simultaneous Luminex Assay according to the manufacturer's instructions (Bio-plex cytokine assay, BioRad, Hercules, CA, USA). Cytokines in supernatants of PBMC and monocytes cultures were determined using enzyme-linked immunosorbent assays. TNF- $\alpha$ was determined by a specific ELISA using four antibodies as described previously [23]. IL$1 \beta$, IL-6 and IL-10 were measured by commercial ELISA kits (IL-1 $\beta$ : R\&D systems, Minneapolis, MN, USA; IL-6 and IL-10: Pelikine Compact, Sanquin, Amsterdam, The Netherlands, according to the manufacturer's instructions).

\subsection{Viability assays}

Monocyte viability was assessed using the in vitro toxicology assay kit, [3-(4,5dimethylthiazol-2-yl)-2,5-diphenyl tetrazolium bromide (MTT) based (Sigma-Aldrich). Monocytes were stimulated as described in section 2.2 (22 hours). After stimulation, plates were centrifuged (1700 rpm, $8 \mathrm{~min}), 100 \mu \mathrm{L}$ of supernatant was stored at $-80{ }^{\circ} \mathrm{C}$ 
for cytokine analysis and $10 \mu \mathrm{L}$ of MTT stock solution $(5 \mathrm{mg} / \mathrm{mL})$ was added to the wells. Monocytes were incubated at $37{ }^{\circ} \mathrm{C}$ for an additional 4 hours after which formazan crystals were solubilized and absorbance at $570 \mathrm{~nm}$ was measured in a plate reader. Additionally, lactate dehydrogenase (LDH) was determined in supernatants of PBMCs stimulated for 22 hours as described in section 2.2 .

\subsection{Flow cytometry}

Flow cytometry was performed on PBMCs stimulated as described in section 2.2 (22 hours), After stimulation, plates were centrifuged (1700 rpm, $8 \mathrm{~min}$ ), supernatants were stored at $-80{ }^{\circ} \mathrm{C}$ for cytokine analysis and adherent cells were detached by adding $200 \mu \mathrm{L}$ of ice-cold FACS buffer (PBS with $0.5 \%$ BSA) and incubating the plate for 15 min on ice. Subsequently, cells were collected by vigorous resuspending and scraping of the bottom of the wells and washed twice in ice-cold FACS buffer. TLR2, TLR4 and CD14 expression was determined with the following directly conjugated antibodies: CD282 PE (mouse IgG2a, TLR 2.1 clone, eBioscience, San Diego, CA, USA), CD284 PE-Cy7 (TLR4, mouse IgG2a, HTA125 clone eBioscience), CD14 ECD (mouse IgG2a, RMO52 clone Immunotech, Beckman Coulter, Mijdrecht, The Netherlands). Expression of $\alpha 7 \mathrm{nAChR}$ on monocytes was determined with a primary antibody against $\alpha 7 \mathrm{nAChR}$ (rat IgG1 monoclonal, 319 clone, Abcam, Cambridge, UK) and CD14 ECD followed by a FITC labeled secondary antibody (donkey anti-rat FITC, Beckman Coulter). After antibody incubation, cells were washed with FACS buffer, resuspended and analyzed on 
a Beckman Coulter FC500 flow cytometer. TLR2, TLR4, CD14 and $\alpha 7 n$ AChR expression were analyzed within CD14 positive monocytes.

\subsection{Quantitative PCR and JAK-STAT signaling arrays}

Untouched primary monocytes were isolated as described in section 2.2 and seeded in duplicate at a density of $1 \times 10^{6} /$ well in 24 -well plates in the presence and absence of LPS and nicotinic agonists. After 4 hours, plates were centrifuged (1700 rpm, $8 \mathrm{~min})$ and supernatants were aspirated. Subsequently, RNA was isolated using RNeasy plus mini kits (Qiagen, Venlo, The Netherlands) according to the manufacturer's instructions. RNA concentration was determined using a Nanodrop ND-1000 spectrophotometer (Thermo Scientific). Per experiment, equal amounts of RNA (150-400 ng) were used for cDNA synthesis using iScript cDNA synthesis kits (Bio-Rad). Negative control reactions were performed in the absence of reverse transcriptase.

The sequences of the primer pairs used were:

\begin{tabular}{|c|c|c|}
\hline $\mathrm{R} 2$ & $\begin{array}{l}\text { forward: } \\
\text { reverse: }\end{array}$ & $\begin{array}{l}\text { 5'-GAATCCTCCAATCAGGCTTCTCT-3' } \\
5^{\prime} \text {-GCCCTGAGGGAATGGAGTTTA-3 }\end{array}$ \\
\hline \multirow[t]{2}{*}{ TLR4 } & forward: & 5'-GGCATGCCTGTGCTGAGTT-3' \\
\hline & & 5'-СТGCTACAACAGATACTACAAGCACACT- \\
\hline \multirow{2}{*}{ TNF- $\alpha$} & forward: & 5'-TGGCCCAGGCAGTCAGA-3' \\
\hline & & 5'-GGTTTGCTACAACATGGGCTACA-3' \\
\hline \multirow[t]{2}{*}{ IL-1 $\beta$} & forward: & 5'-CAGCTACGAATCTCCGACCAC-3' \\
\hline & reverse: & 5'-GGCAGGGAACCAGCATCTTC-3' \\
\hline \multirow{2}{*}{ IL-6 } & forward: & 5'-AATTCGGTACATCCTCGACGG-3' \\
\hline & reverse: & 5'-GGTTGTTTTCTGCCAGTGCCT-3' \\
\hline \multirow[t]{2}{*}{ IL-10 } & forward: & 5'-CAACCTGCCTAACATGCTTCG-3' \\
\hline & reverse: & 5'-TCATCTCAGACAAGGCTTGGC-3' \\
\hline \multirow[t]{3}{*}{ CD14 } & forward: & 5'-ACGCCAGAACCTTGTGAGC-3' \\
\hline & & 5'-GCATGGATCTCCACCTCTACTG-3' \\
\hline & forward: & 5'-AAACTCACAGATGGGCAAGG-3' \\
\hline
\end{tabular}




$\begin{array}{lll} & \text { reverse: } & \text { 5'-AGGGAACACTGGAGTTGTGG-3' } \\ \text { B2M } & \text { forward: } & \text { 5'-ATGAGTATGCCTGCCGTGTG-3' } \\ \text { reverse: } & \text { 5'-CCAAATGCGGCATCTTCAAAC-3' }\end{array}$

Primers were obtained from Biolegio (Nijmegen, The Netherlands). The quantitative PCR (qPCR) reaction was performed using Power SybrGreen master mix (Applied Biosystems, Nieuwekerk a/d Ijssel, The Netherlands) on an ABI Prism 7300 Real Time PCR system (Applied Biosystems). Negative control reactions were cycled alongside test samples to ensure the absence of contaminating genomic DNA. The amplification of a single product was ensured by melt-curve analysis for each primer pair. A standard curve constructed from 1:5 serial dilutions of a mixture of cDNA of the samples in the same run was included for each primer pair in every run to perform relative quantification of mRNA expression.

To investigate the involvement of the JAK-STAT signaling pathway we used $\mathrm{RT}^{2}$ Profiler JAK-STAT QPCR arrays (PAHS-039, SABiosciences, Frederick, MD, USA) according to the manufacturer's instructions. For these experiments, isolated monocytes of three different donors were stimulated and mRNA was isolated as described above. Four housekeeping genes, hypoxanthine phosphoribosyltransferase (HPRT1), glyceraldehyde-3-phosphate dehydrogenase (GAPDH), $\beta$-actin (ACTB) and $\beta 2$ microglobulin (B2M) present on the PCR array were used for normalization.

\subsection{Calculations}

Data are expressed as mean \pm SEM except for whole blood stimulation data which is expressed as median \pm interquartile range as it was not normally distributed. Statistical 
significance in the dose-response curves of nicotine and GTS-21 was evaluated using repeated measures one-way analysis of variance with Bonferroni post-hoc test. Elsewhere, the paired student's t-test was used to test for statistical significance except for the whole blood data which was analyzed using the Wilcoxon matched pairs test and the qPCR JAK-STAT array data for which the analysis procedure is described below. A $\mathrm{p}$-value below 0.05 (except for qPCR JAK-STAT array data, $\mathrm{p}<0.01$ ) was considered statistically significant.

For whole blood experiments, $\%$ inhibition/stimulation was calculated as follows: (TLRagonist-induced cytokine release in the presence of GTS-21 or nicotine / TLR-agonistinduced cytokine release in the absence of GTS-21 or nicotine) - 100. If more than 50\% of the subjects had a cytokine response in response to a TLR-agonist in the absence of a nicotinic agonist that was lower than 4 times the detection limit, no inhibition/stimulation calculations for this TLR-agonist-cytokine combination were performed.

In the experiments where $\mathrm{nAChR}$ antagonists were used, the \% blocking effect of the nAChR antagonists was calculated by subtracting the $\%$ inhibition of the LPS-response by GTS-21 or nicotine in absence of the nAChR antagonist from the \% inhibition of the LPS-response by GTS- 21 or nicotine in the presence of the nAChR antagonist. qPCR data was analyzed using ABI Prism software and calculations were performed as follows: per sample the relative quantity of mRNA of the gene of interest (e.g. TNF- $\alpha$ ) was divided by the relative quantity of the housekeeping gene B2M. To calculate fold induction compared to the control sample, we divided the TNF- $\alpha / \mathrm{B} 2 \mathrm{M}$ ratio by the TNF$\alpha / \mathrm{B} 2 \mathrm{M}$ ratio of the unstimulated control (RPMI) sample. If fold induction was $<1$, it was represented as -(1/fold induction). 
For the JAK-STAT qPCR array experiments each replicate cycle threshold (CT) was normalized to the average CT of four housekeeping genes on a per plate basis. The $2^{-\triangle \Delta C T}$ method was used to calculate the relative quantification of gene expression in stimulated samples compared to RPMI samples. A gene was considered not detectable when CT $>35$. CT was defined as 35 for the $2^{-\triangle \Delta C T}$ calculation when the signal was below detectable limits. If for a specific gene both the stimulated and control sample expression was below detectable limits the sample was excluded from analysis. Genes were considered differentially expressed if mean up- or downregulation was equal or greater than 2 -fold and $\mathrm{p}<0.01$ (permutation test, 100 permutations).

Statistical calculations were performed using Graphpad Prism V4.03 (Graphpad software) except for the permutation tests in the JAK-STAT qPCR array experiments which were analyzed with Multi-experiment Viewer V4.3 (TM4 software suite). 


\section{Results}

\subsection{Nicotine and GTS-21 dose-dependently inhibit LPS-induced cytokine production in} PBMCs

To determine the effect of nAChR agonists on LPS-induced cytokine release we incubated human PBMCs with $1 \mathrm{ng} / \mathrm{mL}$ LPS in combination with nicotine or GTS-21 for 22 hours. The classic nAChR agonist nicotine dose-dependently inhibited production of the pro-inflammatory cytokines TNF- $\alpha$, IL-1 $\beta$ and IL-6 (figure 1 ) with a maximum inhibition of $30 \pm 4 \%, 65 \pm 2 \%$ and $36 \pm 5 \%$ respectively at the highest dose of nicotine used $(1 \mathrm{mM})$. The anti-inflammatory cytokine IL-10 was relatively unaffected, with a small but significant inhibition at a submaximal concentration of nicotine $(21 \pm 3 \%$ at $100 \mu \mathrm{M})$. The selective $\alpha 7 \mathrm{nAChR}$ agonist GTS-21 also dose-dependently inhibited TNF- $\alpha$ and IL$1 \beta$ (figure 2), but was more potent and efficacious than nicotine with a maximum inhibition of $87 \pm 2 \%\left(\mathrm{IC}_{50}: 8.9 \mu \mathrm{M}\right)$ and $89 \pm 3 \%\left(\mathrm{IC}_{50}: 17.9 \mu \mathrm{M}\right)$ respectively at the highest dose of GTS-21 used (100 $\mu$ M). Production of IL-6 was not affected by GTS-21. IL-10 was only inhibited by the highest dose of GTS-21 used $(42 \pm 20 \%$ at $100 \mu \mathrm{M})$ but not at 10 $\mu \mathrm{M}$ GTS-21, a dose which strongly inhibited release of TNF- $\alpha$ and IL-1 $\beta$.

\subsection{Inhibition of pro-inflammatory cytokine production by nicotine and GTS-21 is mediated by monocytes and does not involve cell death}

To investigate which cell type is involved in the inhibition of pro-inflammatory cytokine production by $\mathrm{nAChR}$ agonists we performed stimulation experiments on isolated 
primary human monocytes using the same experimental conditions as in PBMCs. GTS21 and nicotine both significantly inhibited TNF- $\alpha$ production to a similar extent as in PBMCs with GTS-21 showing a distinctively more pronounced effect than nicotine $(84 \pm 3 \%$ and $39 \pm 8 \%$ respectively, figure $3 \mathrm{~A})$. To exclude the possibility that loss of viability or cell death was responsible for the observed inhibition of cytokine production we performed MTT viability assays on the stimulated monocytes which revealed no loss of cell viability with any of the stimuli used (figure 3B). Moreover, lactate dehydogenase levels in supernatants of stimulated PBMCs were not elevated compared to control (RPMI) in any of the samples ( $\mathrm{n}=4$; RPMI 75.3 $\pm 6.2 \mathrm{U} / \mathrm{L}, \mathrm{LPS}$ 72.0 $\pm 5.8 \mathrm{U} / \mathrm{L}, \mathrm{GTS}-21100$

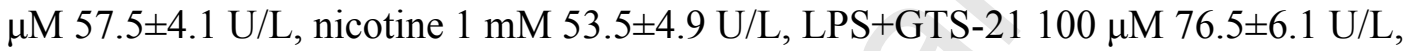
LPS+nicotine $1 \mathrm{mM} 66.0 \pm 3.4 \mathrm{U} / \mathrm{L})$.

3.3 Inhibition of pro-inflammatory cytokine production by nicotine and GTS-21 is not restricted to a specific TLR stimulated

Pattern recognition of the diverse classes of microbial products causing infection involves various TLRs that modulate the subsequent immune response and cytokine profiles [24]. To explore whether the anti-inflammatory effects of nicotine and GTS-21 are dependent on a specific TLR stimulated we incubated human whole blood cultures with TLR2 (Pam3Cys, $1 \mu \mathrm{g} / \mathrm{mL}$ ), TLR3 (PolyI:C, $50 \mu \mathrm{g} / \mathrm{mL}$ ), TLR4 (LPS, $1 \mathrm{ng} / \mathrm{mL}$ ) and TLR5 (flagellin, $1 \mu \mathrm{g} / \mathrm{mL}$ ) agonists in combination with nicotine and GTS-21. Incubation with TLR2, TLR4 and TLR5 agonists resulted in production of pro- (TNF- $\alpha$, IL-1 $\beta$, IL-6, and IFN- $\gamma$ ) as well as anti-inflammatory (IL-10) cytokines (data not shown). The TLR3 
agonist PolyI:C only evoked a robust IL- 6 release while TNF- $\alpha$ and IFN- $\gamma$ were secreted in very small quantities in whole blood cultures of some but not all of the subjects (and therefore were excluded from inhibition/stimulation calculations). PolyI:C did not result in release of IL-1 $\beta$ and IL-10 in whole blood of any of the subjects.

Co-incubation with $100 \mu \mathrm{M}$ of nicotine inhibited TLR-agonist induced pro-inflammatory cytokine release in a mild fashion (data not shown) but $1 \mathrm{mM}$ of nicotine inhibited cytokine release up to $100 \%$, independent on the TLR stimulated (figure 4 , upper panel). The anti-inflammatory cytokine IL-10 was not significantly inhibited by either $100 \mu \mathrm{M}$ or $1 \mathrm{mM}$ of nicotine.

The selective $\alpha 7 \mathrm{nAChR}$ agonist GTS-21 $(100 \mu \mathrm{M})$ also significantly inhibited nearly all TLR-agonist induced pro-inflammatory cytokines (up to $95 \%$ inhibition, figure 4 , lower panel). As with nicotine, GTS-21 did not attenuate the anti-inflammatory cytokine IL-10 release to a great extent, only TLR5-induced IL-10 production was significantly inhibited.

\subsection{Nicotinic antagonists do not restore cytokine production}

As the $\alpha 7 \mathrm{nAChR}$ has been proposed as the receptor responsible for the anti-inflammatory effect of nicotinic agonists [6], we attempted to reverse the effects of nicotine and GTS21 with nAChR antagonists. However, co-incubation with both $\alpha 7 \mathrm{nAChR}$-specific antagonists $\alpha$-bungarotoxin $(10 \mathrm{nM}-1 \mu \mathrm{M})$ and methyllycaconitine $(10 \mu \mathrm{M})$ as well as non-specific nAChR antagonists mecamylamine $(10 \mathrm{nM}-100 \mu \mathrm{M})$ and d-tubocurarine (10-100 $\mu \mathrm{M})$ could not reverse the anti-inflammatory effects of any of the concentrations 
of nicotine \& GTS-21. Inhibition of the GTS-21 $(100 \mu \mathrm{M})$ induced attenuation of the cytokine response by the highest concentration of the nAChR blockers was: $\alpha$ bungarotoxin $1.9 \pm 1.3 \%(\mathrm{n}=6)$, methyllycaconitine $-2.9 \pm 1.0 \%(\mathrm{n}=4)$, mecamylamine $1.8 \pm 3.2 \%(\mathrm{n}=6), \mathrm{d}$-tubocurarine $2.8 \pm 2.8 \%(\mathrm{n}=4) . \%$ inhibition of the nicotine $(1 \mathrm{mM})$ induced cytokine attenuation by the highest concentration of the various nAChR blockers was: $\alpha$-bungarotoxin $5.7 \pm 3.4 \%(n=6)$, methyllycaconitine $0.6 \pm 6.9 \%(n=4)$, mecamylamine $2.3 \pm 4.1 \%(\mathrm{n}=6)$, d-tubocurarine $-10.3 \pm 8.1 \%(\mathrm{n}=4)$. Co-incubation of other concentrations of GTS-21/nicotine with the various concentrations of the nAChR blockers mentioned above was also ineffective in blocking anti-inflammatory effects (data not shown).

\subsection{GTS-21 downregulates cell surface receptors on monocytes}

To obtain more insight into the mechanisms by which nicotine and GTS-21 exhibit their anti-inflammatory effects, we stimulated human PBMCs with LPS in combination with nicotine and GTS-21 and determined cell surface expression of TLR2, TLR4, $\alpha 7 \mathrm{nAChR}$ and CD14 on the monocyte fraction by flow cytometry. We chose the 22-hour incubation based on similar experiments where LPS induced significant upregulation of TLR2 and TLR4 after 24 hours of incubation [25]. As depicted in figure 5, LPS incubation upregulated monocyte cell-surface expression of TLR2 and TLR4 compared to control (RPMI). CD14 expression was also upregulated by LPS (2990 \pm 237.8 vs. $2173 \pm 227.3, \mathrm{p}<0.05)$. GTS-21 inhibited LPS-induced upregulation of TLR2 and CD14 ( $2467 \pm 218.9, \mathrm{p}<0.05$ compared to LPS) and abolished LPS-induced TLR4 upregulation. 
Moreover, in the absence of LPS, GTS-21 lowered TLR4 expression below control levels. LPS had no effect on $\alpha 7 \mathrm{nAChR}$ expression, while GTS-21 in the absence of LPS inhibited $\alpha 7 \mathrm{nAChR}$ expression below control level ( $387 \pm 50.6$ vs. $713.3 \pm 116.3, \mathrm{p}<0.05)$. Nicotine had no effects on expression of any of the measured receptors (data not shown).

3.6 GTS-21, but not nicotine, regulates cytokine production at the transcriptional level

To investigate whether the anti-inflammatory effects of GTS-21 and nicotine are transcriptionally regulated we assessed mRNA levels of pro- and anti-inflammatory cytokines and receptors using quantitative PCR on isolated monocytes stimulated for 4 hours. As expected, incubation with LPS significantly upregulated TNF- $\alpha$, IL-1 $\beta$, IL-6 and IL-10 mRNA expression (respectively 5.4, 14.7, 1715 and 9.7-fold compared to RPMI, figure 6). GTS-21 significantly attenuated LPS-induced upregulation of TNF- $\alpha$ and IL-1 $\beta$ (-2.1 and 4.1-fold compared to RPMI respectively). Moreover, GTS-21 in the absence of LPS significantly decreased TNF- $\alpha$ mRNA levels (-9.6-fold compared to RPMI) while there was a trend towards IL-1 $\beta$ downregulation (-11.9-fold compared to RPMI). There was also a trend towards inhibition of LPS-induced upregulation of IL-6 and IL-10 expression (637.8 and 5-fold compared to RPMI respectively) by GTS-21 as well as downregulation of IL-10 in the absence of LPS (-4.5 compared to RPMI). TLR2 and TLR4 mRNA expression was not altered by LPS. GTS-21 significantly downregulated TLR2 in the absence of LPS (-3.2-fold compared to RPMI) but had no effect on TLR4 mRNA levels. LPS significantly downregulated CD14 (data not shown, -5.6 fold compared to RPMI), this was inhibited by GTS-21 (-3.5 fold compared to 
RPMI). Nicotine did not alter expression of any of the cytokine genes assessed (data not shown). $\alpha 7 \mathrm{nAChR}$ gene expression was not altered by any stimulus (data not shown).

\subsection{The anti-inflammatory effect of GTS-21 and nicotine are dependent on JAK2 phosphorylation}

To evaluate the involvement of the JAK-STAT pathway in the anti-inflammatory effects of nicotine and GTS-21 we incubated PBMCs with LPS, nicotine and GTS-21 in combination with AG490, a selective inhibitor of JAK2 phosphorylation [26,16,17]. 100 $\mu \mathrm{M}$ AG490 inhibited the anti-inflammatory effect of $100 \mu \mathrm{M}$ GTS-21 while completely restoring the attenuated TNF- $\alpha$ production by $10 \mu \mathrm{M}$ GTS- 21 and $1 \mathrm{mM}$ nicotine (figure 7). AG490 alone or vehicle ( $1 \%$ etOH) had no significant effects on LPS-induced TNF- $\alpha$ release (LPS+AG490 2719 379 pg/mL; LPS $+1 \%$ etOH $1666 \pm 333 \mathrm{pg} / \mathrm{mL}$ ).

\subsection{GTS-21 effects are likely mediated by JAK2/STAT3 signaling}

To further explore the role of the JAK-STAT signaling pathway in the anti-inflammatory effects of GTS-21 we used $\mathrm{RT}^{2}$ profiler qPCR arrays which contain a panel of 84 genes related to JAK-STAT-mediated signaling on isolated monocytes. Genes that were significantly and more than twofold up- or downregulated by 4-hour incubations with GTS-21, LPS and LPS+GTS-21 are shown in table 1. GTS-21 clearly inhibited LPSinduced expression of IFN- $\gamma$ and IFN- $\gamma$-inducible genes such as CXCL9, GBP1 and OAS1 $[27,28,29]$. In concordance with the implicated pivotal role for the JAK2-STAT3 
pathway in $\alpha 7 \mathrm{nAChR}$ signaling, GTS-21 upregulated STAT3 expression in the presence of LPS. Furthermore, LPS-induced downregulation of F2 (thrombin), an activator of JAK2/STAT3 pathway and SH2B1, a JAK2 activator, were abolished by GTS-21 whereas GTS-21 upregulated OSM which is involved in STAT3 phosphorylation and PRLR, a receptor which upon ligand binding activates JAK2 [30,31,32,33]. In the presence of LPS, GTS-21 induced upregulation of PTPN1, a protein tyrosine phosphatase which dephosphorylates JAK2, which may represent a negative feedback mechanism preventing excessive JAK2 activation [34]. STAT5A was upregulated by GTS-21 in the presence of LPS while LPS-induced downregulation of STAT5B was blocked by GTS-21 indicating activation of the JAK2-STAT5 pathway. The transcription of NFKB and SOCS3 was upregulated by LPS but not affected by co-incubation with GTS-21. 


\section{Discussion}

The cholinergic anti-inflammatory pathway may represent new treatment options for inflammatory conditions such as sepsis, acute lung injury and autoimmune diseases. Vagus nerve stimulation in humans is a very invasive procedure and is not feasible in acute situations. Therefore, pharmacological stimulation of the cholinergic antiinflammatory pathway via the $\alpha 7 \mathrm{nAChR}$ is a more practical approach. The non-specific $\mathrm{nAChR}$ agonist nicotine has little therapeutic potential because of its toxicity and other unwanted side effects. We are the first to show that GTS-21, a compound acting specifically at the $\alpha 7 \mathrm{nAChR}$, is a strong inhibitor of pro-inflammatory cytokine release in primary human leukocytes while leaving anti-inflammatory cytokine production relatively unaffected. Nicotine has similar effects, but much less pronounced. Therefore, GTS-21 causes a profound shift in the pro-/anti-inflammatory balance towards an antiinflammatory phenotype. While earlier reports state that the anti-inflammatory effect of $\alpha 7 \mathrm{nAChR}$ stimulation relies on a post-transcriptional mechanism $[4,16]$ we present evidence that GTS-21 attenuates the inflammatory response at the transcriptional level.

In our study, GTS-21 and nicotine exerted their anti-inflammatory effects equally on PBMCs and isolated monocytes suggesting that these effects are mainly monocytemediated. However, because the monocyte isolation method we employed does not yield completely pure monocytes, effects of the nicotinic agonists on lymphocytes or other cell types present in PBMCs cannot be ruled out. In this respect it is of note that in whole blood experiments the T-cell/NK-cell cytokine IFN- $\gamma$ was significantly inhibited by both 
nicotinic agonists. Non-activated lymphocytes generally are not noted for TLR-responses but NK cells have been reported to produce IFN- $\gamma$ after TLR-stimulation [35]. Whether the observed inhibition of IFN- $\gamma$ production represents a direct inhibitory effect on NKcells or an indirect effect via attenuation of cytokines that stimulate TLR-induced IFN- $\gamma$ production by these cells such as IL-12 and TNF- $\alpha$, has to be determined. Nonetheless, while we have focused on the effects of GTS-21 and nicotine on innate immune responses, an effect on the adaptive immune system by these compounds is anticipated because of alterations in co-stimulatory factors, cell interactions and interplay between cytokines. Moreover, since primary human lymphocytes express the $\alpha 7 \mathrm{nAChR}$, a direct effect of $\alpha 7 \mathrm{nAChR}$ agonists on these cells and the adaptive immune response should not be neglected $[36,37]$. The lack of an inhibitory effect on IL-6 release by GTS- 21 is in line with a study in mice which demonstrates a rather selective effect of GTS-21 on TNF- $\alpha$ release [8,37]. There was a trend towards lower IL-6 mRNA levels in GTS-21-treated monocytes but it did not reach statistical significance.

We further demonstrate that the anti-inflammatory effects of both nicotine and GTS-21 are not specific for the TLR stimulated using a whole blood stimulation assay. This is important because pattern recognition of the diverse classes of microbial products involves various TLRs that modulate the subsequent immune response [24,38]. As a consequence, cytokine release profiles evoked by Gram-positive bacteria, Gram-negative bacteria, viruses and various endogenous agonists differ. Previous work in our group has shown that the effect of immunomodulating compounds can differ depending on the TLR stimulated [39]. The data in this paper illustrate that both nicotinic compounds exhibit a generalized anti-inflammatory effect not dependent on the inflammatory stimulus and 
therefore not confined to a specific sort of infection or endogenous stimulus.

Additionally, we affirm the anti-inflammatory potential of GTS-21 and nicotine in whole blood containing all cell types and humoral factors present, which is more reflective of in vivo conditions than an isolated cell model.

While the $\alpha 7 \mathrm{nAChR}$ has been identified as the pivotal receptor in the cholinergic antiinflammatory pathway [6], we could not reverse the actions of nicotine or GTS-21 with antagonists of this receptor ( $\alpha$-bungarotoxin and MLA) or with non-specific nAChR antagonists (mecamylamine and d-tubocurarine) in human immune cells. In accordance, for nicotine, blockade of the anti-inflammatory effect by $\alpha$-bungarotoxin has been described by some $[16,40]$ but not all $[41]$. To date, no attempts have been made to reverse the anti-inflammatory effect of GTS-21 by nAChR antagonists. There are a number of possible reasons to explain the failure to block GTS-21 and nicotine effects by $\alpha 7$ antagonists. First of all the possibility remains that some of the nicotine or GTS-21 effects in human leukocytes are mediated by a non- $\alpha 7 \mathrm{nAChR}$-related mechanism which remains to be elucidated. Another explanation might rely on differences in the $\alpha 7 \mathrm{nAChR}$ between cell types. In excitable neuronal cells, $\alpha 7 \mathrm{nAChRs}$ are ligand-gated ion channels composed of $5 \alpha 7$ subunits which upon activation cause depolarization of the cell membrane and influx of $\mathrm{Ca}^{2+}$ via voltage-operated $\mathrm{Ca}^{2+}$ channels. However, leukocytes do not possess these $\mathrm{Ca}^{2+}$ channels and it was demonstrated that in PBMCs $\alpha 7 \mathrm{nAChRs}$ stimulation by nicotine or acetylcholine does not result in detectable membrane currents while it does in neuronal cells [42]. Others have demonstrated that, despite the fact that T-cells express an essentially identical transcript for the $\alpha 7 \mathrm{nAChR}$ subunit as neuronal 
cells, they do not form functional ligand-gated ion channels [37]. Furthermore, it was shown that leukocytes do not express the "normal" $\alpha 7$ subunit, but an $\alpha 7$ duplicate nicotinic acetylcholine receptor-related protein (dup $\alpha$ 7) which lacks the $\alpha$-bungarotoxin binding site and has most likely different pharmacological properties [42]. This is supported by the aforementioned study in T-cells, where the $\alpha 7 \mathrm{nAChR}$ specific antagonist MLA and $\alpha$-bungarotoxin did not inhibit nicotine-induced effects [37]. Different pharmacological properties may also explain why the partial $\alpha 7 \mathrm{nAChR}$ agonist GTS-21 has a much more potent effect on cytokine release in primary human leukocytes than the full agonist nicotine, while in classic $\alpha 7 \mathrm{nAChRs}$, the opposite is true [43]. Interestingly, bone marrow and brain cells were positive for both the normal $\alpha 7$ and the dup $\alpha 7$ subunit [42]. This indicates that the presence of the normal $\alpha 7 \mathrm{nAChR}$ or the dup $\alpha 7$ might vary between different cell types, which could explicate why nicotinic blockers antagonize $\alpha 7 \mathrm{nAChR}$ in some cell types but not in others.

LPS-induced increases in monocyte cell-surface expression of TLR2 and TLR4 have been described previously [25]. We confirm these findings and demonstrate that LPS also increases cell surface expression of CD14 which is essential in LPS-induced cytokine production [44]. GTS-21, but not nicotine, inhibits TLR and CD14 upregulation and this could play a role in the diminished pro-inflammatory cytokine production in GTS-21 treated leukocytes since modulation of cell-surface expression of TLR4 has been linked to the degree of cytokine production [45]. The observed LPS-induced upregulation of TLRs could also be mediated by cytokine production, so-called "priming", which would explain why the non-TLR2 agonist LPS increases TLR2 expression [46]. In this respect 
inhibition of cell-surface expression of the TLRs by GTS-21 might be a result of inhibition of cytokines rather than a cause. mRNA levels of TLR4 and TLR2 were not affected by LPS and only TLR2 mRNA expression was modestly inhibited by GTS-21. The discrepancies between TLR protein and mRNA expression might result from the different incubation period used in the protein expression experiments compared to the mRNA experiments (22 hours vs. 4 hours) but can also indicate that the modulation of TLR cell-surface expression relies mainly on post-transcriptional mechanisms. An earlier report demonstrates that nicotine downregulates cell-surface expression of TLR4 and CD14 on human monocytes [47]. This discrepancy with our study might be explained by the modest anti-inflammatory effect of nicotine in our experiments.

De Jonge et al. have demonstrated that the anti-inflammatory effect of nicotine in murine macrophages acts through the recruitment of JAK2 to the $\alpha 7 \mathrm{nAChR}$ and subsequent phosphorylation of JAK2, thereby initiating the anti-inflammatory STAT3 cascade [16]. We show that in primary human leukocytes both GTS-21 and nicotine effects could be inhibited by AG490, a JAK2 phosphorylation inhibitor, confirming a pivotal role for JAK2 activation. We further explored activation of the JAK-STAT pathway using quantitative PCR arrays. Although these arrays do not provide data on phosphorylation of JAK-STAT family members, it evaluates expression of known activators/inhibitors of this signaling cascade at the transcriptional level. Our results indicate that GTS-21 strongly downregulates IFN- $\gamma$-inducible genes related to STAT1 activation in monocytes [48]. Therefore, as stated before, GTS-21 may have a pronounced inhibitory effect on the adaptive immune response which warrants future research. JAK2/STAT3 signaling 
appeared to be activated by GTS-21 reflected by increased expression of STAT3, receptors activating JAK2 (PRLR) and activators of STAT3 (OSM). Furthermore, GTS21 blocked LPS-induced downregulation of JAK2/STAT3 activators (F2, SH2B1). The upregulation of STAT5A and the blockade of LPS-induced downregulation of STAT5B by GTS-2 1 further indicate JAK2 activity as STAT5 is also activated by JAK2 in monocytes [49].

There is much debate regarding the pro- and anti-inflammatory roles of STAT3 which appear to be highly cell- and stimulation-specific. A number of studies implicate proinflammatory actions of STAT3, such as a recent paper describing the critical role of STAT3 activation in IL-1 $\beta$ and IL-6 production in a RAW 264.7 macrophage cell line [50]. However, there is also a large body of evidence associating STAT3 activity with anti-inflammatory effects. For instance, STAT3 is essential for responsiveness to IL-10 which is known to deactivate macrophages [51,52] and STAT3 deficient macrophages are constitutively activated and secrete large amounts of pro-inflammatory mediators [52]. Blocking STAT3 in tumor cells increases expression of pro-inflammatory cytokines and mice lacking STAT3 in macrophages and neutrophils are highly susceptible to endotoxic shock $[52,53]$. Moreover, mice bearing a STAT3 deletion in bone marrow cells display higher levels of circulating TNF- $\alpha$ and IFN- $\gamma$ a compared to control mice in the absence of an inflammatory process [54]. The mechanism by which GTS-21 (and probably nicotine) inhibits cytokine release may rely on enhanced IL-10 signaling or actions mimicking IL-10 signaling resulting in STAT3 activation. Because IL-10 downregulates its own production, excessive IL-10 signaling could account for the 
inhibited production of IL-10 observed with the highest dose of GTS-21 used (100 $\mu \mathrm{M})$ [51].

Similar to what has been reported for nicotine [16], SOCS3 appears not to play a role in the anti-inflammatory effects of GTS-21 while the LPS-induced upregulation of SOCS3 was not further enhanced by GTS-21. Our quantitative PCR experiments illustrate that GTS-21 inhibits LPS-induced upregulation of pro-inflammatory cytokines at the transcriptional level. While others argue that the anti-inflammatory effects of $\alpha 7 \mathrm{nAChR}$ stimulation predominantly rely on post-transcriptional modulation $[4,16]$, our data are in accordance with IL-10 (-like) signaling which inhibits TNF- $\alpha$ production at both the transcriptional and the translational level [55]. Moreover, GTS-21 and nicotine both have been reported to inhibit LPS-induced NFKB activation which implies transcriptional modulation $[7,20,21]$. While our JAK-STAT array results demonstrate that the transcription of NFאB is not upregulated by GTS-21 compared to LPS, this does not exclude the possibility that GTS-21 modulates NFkB activity/nuclear translocation as this is not dependent on transcription or translation [56]. Nicotine did not affect mRNA levels of any of the genes assessed. Whether this is due to the relatively low anti-inflammatory potential nicotine displayed in our experiments or to other factors remains to be elucidated.

In conclusion, GTS-21 represents novel opportunities for human research into the cholinergic anti-inflammatory pathway and possibly for future therapeutic applications. It is more effective than nicotine in modulating the immune response in human leukocytes 
1

2

and its suitability for human use makes it a candidate for human in vivo trials to further explore the cholinergic anti-inflammatory pathway. 


\section{Acknowledgements}

The authors would kindly like to thank Prof. Dr. Roger L. Papke of the University of

Florida and Comentis inc. for supplying us with GTS-21 and Trees Jansen for help with the Luminex cytokine measurements. M. Kox and J.C. Pompe are recipients of a grant of the Radboud University Nijmegen Medical Centre Trauma Section/Intensive Care Medicine. 
[1] Fleshner M, Goehler LE, Schwartz BA, McGorry M, Martin D, Maier SF, Watkins LR. Thermogenic and corticosterone responses to intravenous cytokines (IL1beta and TNF-alpha) are attenuated by subdiaphragmatic vagotomy. J.Neuroimmunol. 1998; 86:134-141.

[2] Goehler LE, Busch CR, Tartaglia N, Relton J, Sisk D, Maier SF, Watkins LR. Blockade of cytokine induced conditioned taste aversion by subdiaphragmatic vagotomy: further evidence for vagal mediation of immune-brain communication. Neurosci.Lett. 1995; 185:163-166.

[3] Watkins LR, Maier SF, Goehler LE. Immune activation: the role of proinflammatory cytokines in inflammation, illness responses and pathological pain states. Pain 1995; 63:289-302.

[4] Borovikova LV, Ivanova S, Zhang M, Yang H, Botchkina GI, Watkins LR, Wang $\mathrm{H}$, Abumrad N, Eaton JW, Tracey KJ. Vagus nerve stimulation attenuates the systemic inflammatory response to endotoxin. Nature 2000; 405:458462.

[5] Sato KZ, Fujii T, Watanabe Y, Yamada S, Ando T, Kazuko F, Kawashima K. Diversity of mRNA expression for muscarinic acetylcholine receptor subtypes and neuronal nicotinic acetylcholine receptor subunits in human mononuclear leukocytes and leukemic cell lines. Neurosci.Lett. 1999; 266:17-20.

[6] Wang H, Yu M, Ochani M, Amella CA, Tanovic M, Susarla S, Li JH, Wang H, Yang H, Ulloa L, Al-Abed Y, Czura CJ, Tracey KJ. Nicotinic acetylcholine receptor alpha7 subunit is an essential regulator of inflammation. Nature 2003 ; 421:384-388.

[7] Pavlov VA, Ochani M, Yang LH, Gallowitsch-Puerta M, Ochani K, Lin X, Levi J, Parrish WR, Rosas-Ballina M, Czura CJ, Larosa GJ, Miller EJ, Tracey KJ, Al-Abed Y. Selective alpha7-nicotinic acetylcholine receptor agonist GTS21 improves survival in murine endotoxemia and severe sepsis. Crit Care Med. 2007; 35:1139-1144.

[8] Giebelen IA, van Westerloo DJ, Larosa GJ, de Vos AF, van der PT. Stimulation of alpha7 cholinergic receptors inhibits lipopolysaccharide-induced neutrophil recruitment by a tumor necrosis factor alpha-independent mechanism. Shock 2007; 27:443-447.

[9] van Westerloo DJ, Giebelen IA, Florquin S, Bruno MJ, Larosa GJ, Ulloa L, Tracey $\mathrm{KJ}$, van der PT. The vagus nerve and nicotinic receptors modulate experimental pancreatitis severity in mice. Gastroenterology 2006; 130:1822-1830. 
[10] Giebelen IA, van Westerloo DJ, Larosa GJ, de Vos AF, van der PT. Local stimulation of alpha7 cholinergic receptors inhibits LPS-induced TNF-alpha release in the mouse lung. Shock 2007; 28:700-703.

[11] Su X, Lee JW, Matthay ZA, Mednick G, Uchida T, Fang X, Gupta N, Matthay MA. Activation of the alpha7 nAChR reduces acid-induced acute lung injury in mice and rats. Am.J.Respir.Cell Mol.Biol. 2007; 37:186-192.

[12] Yeboah MM, Xue X, Duan B, Ochani M, Tracey KJ, Susin M, Metz CN. Cholinergic agonists attenuate renal ischemia-reperfusion injury in rats. Kidney Int. 2008; 74:62-69.

[13] Kitagawa H, Takenouchi T, Azuma R, Wesnes KA, Kramer WG, Clody DE, Burnett AL. Safety, pharmacokinetics, and effects on cognitive function of multiple doses of GTS-21 in healthy, male volunteers. Neuropsychopharmacology 2003; 28:542-551.

[14] Meyer EM, Kuryatov A, Gerzanich V, Lindstrom J, Papke RL. Analysis of 3-(4hydroxy, 2-Methoxybenzylidene)anabaseine selectivity and activity at human and rat alpha-7 nicotinic receptors. J.Pharmacol.Exp.Ther. 1998; 287:918-925.

[15] Stokes C, Papke JK, Horenstein NA, Kem WR, McCormack TJ, Papke RL. The structural basis for GTS-21 selectivity between human and rat nicotinic alpha7 receptors. Mol.Pharmacol. 2004; 66:14-24.

[16] de Jonge WJ, van der Zanden EP, The FO, Bijlsma MF, van Westerloo DJ, Bennink RJ, Berthoud HR, Uematsu S, Akira S, van den Wijngaard RM, Boeckxstaens GE. Stimulation of the vagus nerve attenuates macrophage activation by activating the Jak2-STAT3 signaling pathway. Nat.Immunol. $2005 ; 6: 844-851$.

[17] Shaw S, Bencherif M, Marrero MB. Janus kinase 2, an early target of alpha 7 nicotinic acetylcholine receptor-mediated neuroprotection against Abeta-(142) amyloid. J.Biol.Chem. 2002; 277:44920-44924.

[18] Arredondo J, Chernyavsky AI, Jolkovsky DL, Pinkerton KE, Grando SA. Receptormediated tobacco toxicity: cooperation of the Ras/Raf-1/MEK1/ERK and JAK-2/STAT-3 pathways downstream of alpha7 nicotinic receptor in oral keratinocytes. FASEB J. 2006; 20:2093-2101.

[19] Osborne-Hereford AV, Rogers SW, Gahring LC. Neuronal nicotinic alpha7 receptors modulate inflammatory cytokine production in the skin following ultraviolet radiation. J.Neuroimmunol. 2008; 193:130-139.

[20] Sugano N, Shimada K, Ito K, Murai S. Nicotine inhibits the production of inflammatory mediators in U937 cells through modulation of nuclear factorkappaB activation. Biochem.Biophys.Res.Commun. 1998; 252:25-28. 
[21] Yoshikawa H, Kurokawa M, Ozaki N, Nara K, Atou K, Takada E, Kamochi H, Suzuki N. Nicotine inhibits the production of proinflammatory mediators in human monocytes by suppression of I-kappaB phosphorylation and nuclear factor-kappaB transcriptional activity through nicotinic acetylcholine receptor alpha7. Clin.Exp.Immunol. 2006; 146:116-123.

[22] Hirschfeld M, Ma Y, Weis JH, Vogel SN, Weis JJ. Cutting edge: repurification of lipopolysaccharide eliminates signaling through both human and murine toll-like receptor 2. J.Immunol. 2000; 165:618-622.

[23] Grebenchtchikov N, van d, V, Pesman GJ, Geurts-Moespot A, van der Meer JW, Sweep FC. Development of a sensitive ELISA for the quantification of human tumour necrosis factor-alpha using 4 polyclonal antibodies. Eur.Cytokine Netw. 2005; 16:215-222.

[24] Akira S, Hemmi H. Recognition of pathogen-associated molecular patterns by TLR family. Immunol.Lett. 2003; 85:85-95.

[25] Wittebole X, Coyle SM, Kumar A, Goshima M, Lowry SF, Calvano SE. Expression of tumour necrosis factor receptor and Toll-like receptor 2 and 4 on peripheral blood leucocytes of human volunteers after endotoxin challenge: a comparison of flow cytometric light scatter and immunofluorescence gating. Clin.Exp.Immunol. 2005; 141:99-106.

[26] Meydan N, Grunberger T, Dadi H, Shahar M, Arpaia E, Lapidot Z, Leeder JS, Freedman M, Cohen A, Gazit A, Levitzki A, Roifman CM. Inhibition of acute lymphoblastic leukaemia by a Jak-2 inhibitor. Nature 1996; 379:645648.

[27] Cole AM, Ganz T, Liese AM, Burdick MD, Liu L, Strieter RM. Cutting edge: IFNinducible ELR- CXC chemokines display defensin-like antimicrobial activity. J.Immunol. 2001; 167:623-627.

[28] Nantais DE, Schwemmle M, Stickney JT, Vestal DJ, Buss JE. Prenylation of an interferon-gamma-induced GTP-binding protein: the human guanylate binding protein, huGBP1. J.Leukoc.Biol. 1996; 60:423-431.

[29] Rebouillat D, Hovanessian AG. The human 2',5'-oligoadenylate synthetase family: interferon-induced proteins with unique enzymatic properties. J.Interferon Cytokine Res. 1999; 19:295-308.

[30] Huang C, Ma R, Sun S, Wei G, Fang Y, Liu R, Li G. JAK2-STAT3 signaling pathway mediates thrombin-induced proinflammatory actions of microglia in vitro. J.Neuroimmunol. 2008; 204:118-125.

[31] Sakamoto K, Creamer BA, Triplett AA, Wagner KU. The Janus kinase 2 is required for expression and nuclear accumulation of cyclin D1 in proliferating mammary epithelial cells. Mol.Endocrinol. 2007; 21:1877-1892. 
[32] O'Brien KB, O'Shea JJ, Carter-Su C. SH2-B family members differentially regulate JAK family tyrosine kinases. J.Biol.Chem. 2002; 277:8673-8681.

[33] Heinrich PC, Behrmann I, Haan S, Hermanns HM, Muller-Newen G, Schaper F. Principles of interleukin (IL)-6-type cytokine signalling and its regulation. Biochem.J. 2003; 374:1-20.

[34] Myers MP, Andersen JN, Cheng A, Tremblay ML, Horvath CM, Parisien JP, Salmeen A, Barford D, Tonks NK. TYK2 and JAK2 are substrates of protein-tyrosine phosphatase 1B. J.Biol.Chem. 2001; 276:47771-47774.

[35] Lauzon NM, Mian F, MacKenzie R, Ashkar AA. The direct effects of Toll-like receptor ligands on human NK cell cytokine production and cytotoxicity. Cell Immunol. 2006; 241:102-112.

[36] De Rosa MJ, Esandi MC, Garelli A, Rayes D, Bouzat C. Relationship between alpha $7 \mathrm{nAChR}$ and apoptosis in human lymphocytes. J.Neuroimmunol. 2005; 160:154-161.

[37] Razani-Boroujerdi S, Boyd RT, vila-Garcia MI, Nandi JS, Mishra NC, Singh SP, Pena-Philippides JC, Langley R, Sopori ML. T cells express alpha7nicotinic acetylcholine receptor subunits that require a functional TCR and leukocyte-specific protein tyrosine kinase for nicotine-induced $\mathrm{Ca} 2+$ response. J.Immunol. 2007; 179:2889-2898.

[38] Armant MA, Fenton MJ. Toll-like receptors: a family of pattern-recognition receptors in mammals. Genome Biol. 2002; 3:3011.1-3011.6.

[39] Ramakers BP, Riksen NP, Rongen GA, van der Hoeven JG, Smits P, Pickkers P. The effect of adenosine receptor agonists on cytokine release by human mononuclear cells depends on the specific Toll-like receptor subtype used for stimulation. Cytokine 2006; 35:95-99.

[40] De SR, jmone-Cat MA, Carnevale D, Minghetti L. Activation of alpha7 nicotinic acetylcholine receptor by nicotine selectively up-regulates cyclooxygenase2 and prostaglandin E2 in rat microglial cultures. J.Neuroinflammation. $2005 ; 2: 4$.

[41] Matsunaga K, Klein TW, Friedman H, Yamamoto Y. Involvement of nicotinic acetylcholine receptors in suppression of antimicrobial activity and cytokine responses of alveolar macrophages to Legionella pneumophila infection by nicotine. J.Immunol. 2001; 167:6518-6524.

[42] Villiger Y, Szanto I, Jaconi S, Blanchet C, Buisson B, Krause KH, Bertrand D, Romand JA. Expression of an alpha7 duplicate nicotinic acetylcholine receptor-related protein in human leukocytes. J.Neuroimmunol. 2002; 126:86-98. 
[43] Stokes C, Papke JK, Horenstein NA, Kem WR, McCormack TJ, Papke RL. The structural basis for GTS-21 selectivity between human and rat nicotinic alpha7 receptors. Mol.Pharmacol. 2004; 66:14-24.

[44] Muta T, Takeshige K. Essential roles of CD14 and lipopolysaccharide-binding protein for activation of toll-like receptor (TLR)2 as well as TLR4 Reconstitution of. Eur.J.Biochem. 2001; 268:4580-4589.

[45] Pearl-Yafe M, Fabian I, Halperin D, Flatau E, Werber S, Shalit I. Interferon-gamma and bacterial lipopolysaccharide act synergistically on human neutrophils enhancing interleukin-8, interleukin-1beta, tumor necrosis factor-alpha, and interleukin-12 p70 secretion and phagocytosis via upregulation of toll-like receptor 4. Shock 2007; 27:226-231.

[46] Bosisio D, Polentarutti N, Sironi M, Bernasconi S, Miyake K, Webb GR, Martin MU, Mantovani A, Muzio M. Stimulation of toll-like receptor 4 expression in human mononuclear phagocytes by interferon-gamma: a molecular basis for priming and synergism with bacterial lipopolysaccharide. Blood 2002; 99:3427-3431.

[47] Hamano R, Takahashi HK, Iwagaki H, Yoshino T, Nishibori M, Tanaka N. Stimulation of alpha7 nicotinic acetylcholine receptor inhibits CD14 and the toll-like receptor 4 expression in human monocytes. Shock 2006; 26:358364.

[48] Liuzzo G, Vallejo AN, Kopecky SL, Frye RL, Holmes DR, Goronzy JJ, Weyand CM. Molecular fingerprint of interferon-gamma signaling in unstable angina. Circulation 2001; 103:1509-1514.

[49] Rosen RL, Winestock KD, Chen G, Liu X, Hennighausen L, Finbloom DS. Granulocyte-macrophage colony-stimulating factor preferentially activates the 94-kD STAT5A and an 80-kD STAT5A isoform in human peripheral blood monocytes. Blood 1996; 88:1206-1214.

[50] Samavati L, Rastogi R, Du W, Huttemann M, Fite A, Franchi L. STAT3 tyrosine phosphorylation is critical for interleukin 1 beta and interleukin-6 production in response to lipopolysaccharide and live bacteria. Mol.Immunol. 2009; 46:1867-1877.

[51] de Waal MR, Abrams J, Bennett B, Figdor CG, de Vries JE. Interleukin 10(IL-10) inhibits cytokine synthesis by human monocytes: an autoregulatory role of IL-10 produced by monocytes. J.Exp.Med. 1991; 174:1209-1220.

[52] Takeda K, Clausen BE, Kaisho T, Tsujimura T, Terada N, Forster I, Akira S. Enhanced Th1 activity and development of chronic enterocolitis in mice devoid of Stat3 in macrophages and neutrophils. Immunity. 1999; 10:39-49. 
[53] Wang T, Niu G, Kortylewski M, Burdelya L, Shain K, Zhang S, Bhattacharya R, Gabrilovich D, Heller R, Coppola D, Dalton W, Jove R, Pardoll D, Yu H. Regulation of the innate and adaptive immune responses by Stat-3 signaling in tumor cells. Nat.Med. 2004; 10:48-54.

[54] Welte T, Zhang SS, Wang T, Zhang Z, Hesslein DG, Yin Z, Kano A, Iwamoto Y, Li E, Craft JE, Bothwell AL, Fikrig E, Koni PA, Flavell RA, Fu XY. STAT3 deletion during hematopoiesis causes Crohn's disease-like pathogenesis and lethality: a critical role of STAT3 in innate immunity. Proc.Natl.Acad.Sci.U.S.A 2003; 100:1879-1884.

[55] Kontoyiannis D, Kotlyarov A, Carballo E, Alexopoulou L, Blackshear PJ, Gaestel M, Davis R, Flavell R, Kollias G. Interleukin-10 targets p38 MAPK to modulate ARE-dependent TNF mRNA translation and limit intestinal pathology. EMBO J. 2001; 20:3760-3770.

[56] Karin M, Ben-Neriah Y. Phosphorylation meets ubiquitination: the control of NF[kappa]B activity. Annu.Rev.Immunol. 2000; 18:621-663. 


\title{
Figure Legends
}

\section{Graphical abstract figure}

Model of GTS-21 signaling in primary human monocytes.

\section{Figure 1}

Dose-response curves of the effect of nicotine on cytokine production in human PBMC stimulated with $1 \mathrm{ng} / \mathrm{mL}$ LPS for 22 hours. Data are represented as mean $\pm \operatorname{SEM}(8$ different donors, two independent experiments). * indicates $\mathrm{p}<0.05$ compared to the LPS response in the absence of nicotine (repeated measures ANOVA with Bonferroni posthoc test).

\section{Figure 2}

Dose-response curves of the effect of GTS-21 on cytokine production in human PBMC stimulated with $1 \mathrm{ng} / \mathrm{mL}$ LPS for 22 hours. Data are represented as mean $\pm \operatorname{SEM}(8$ different donors, two independent experiments). * indicates $\mathrm{p}<0.05$ compared to the LPS response in the absence of GTS-21 (repeated measures ANOVA with Bonferroni posthoc test).

\section{Figure 3}

\begin{abstract}
A) Effect of nicotine and GTS-21 on TNF- $\alpha$ production in isolated primary human monocytes stimulated with LPS $(1 \mathrm{ng} / \mathrm{mL})$ for 22 hours. Both GTS-21(100 $\mu \mathrm{M})$ and nicotine $(1 \mathrm{mM})$ attenuate TNF- $\alpha$ production in isolated monocytes stimulated with LPS.
\end{abstract}


Data are represented as mean $\pm \operatorname{SEM}$ (6 different donors, two independent experiments).

* indicates $\mathrm{p}<0.05$ compared to the LPS alone (paired Student's t-test).

B) MTT viability assay on isolated primary human monocytes stimulated with LPS, nicotine and GTS-21. Percentage viability was calculated relative to viability in the control (RPMI) samples. Data are represented as mean \pm SEM (6 different donors, two independent experiments).

\section{Figure 4}

Percentage inhibition/stimulation of TLR-agonist induced cytokine production in human 1:5 diluted whole blood by $1 \mathrm{mM}$ nicotine and $100 \mu \mathrm{M}$ GTS-21(24-hour stimulation). TLR agonists used were TLR1+2: Pam3Cys $(1 \mu \mathrm{g} / \mathrm{mL})$; TLR3: PolyI:C (50 $\mu \mathrm{g} / \mathrm{ml})$; TLR4: LPS (1 ng/mL); TLR5: flagellin $(1 \mu \mathrm{g} / \mathrm{mL})$. Data are represented as median and interquartile range ( 6 different donors). ${ }^{*}$ indicates $p<0.05$, Wilcoxon Matched Pairs test. Concentrations of cytokines in absence of nicotine or GTS-21 after stimulation with TLR2, TLR3, TLR4 and TLR5 agonists in $\mathrm{pg} / \mathrm{mL}$ (interquartile range) were; TNF- $\alpha: 154$ (41-592), 6 (2-15), 3150 (2020-3927), 2054 (692-4309). IL-6: 1374 (482-4406), 89 (61134), 6979 (4678-9309), 8341 (4864-11842). IL-1ß: 19 (3-80), 0 (0-2), 1637 (922-1963), 1502 (740-2126). IFN- $\gamma 106$ (33- 349), 9 (0-27), 734 (521- 954), 802 (593-1072). IL-10: 43 (6-120), 0 (0-0), 76 (56-116), 221 (99-447).

\section{Figure 5}

Flow cytometric analysis of the effects of LPS $(1 \mathrm{ng} / \mathrm{mL})$ and GTS-21 $(100 \mu \mathrm{M})$ on cellsurface expression of TLR2 and TLR 4 on primary human monocytes incubated for 22 
hours. In the lower panels overlays of histograms depicting TLR2 and TLR4 expression on incubated monocytes of a typical subject are displayed. The dashed line represent isotype control, dark grey represents RPMI, light grey represents LPS and white represents LPS + GTS-21. Data are represented as mean \pm SEM (8 different donors, two independent experiments). \# indicates $\mathrm{p}<0.05$ compared to RPMI, * indicates $\mathrm{p}<0.05$ compared to LPS (paired Student's t-test).

\section{Figure 6}

mRNA expression of TNF- $\alpha$, IL-1 $\beta$, IL-6, IL-10, TLR2 and TLR4 in isolated primary human monocytes stimulated with LPS ( $1 \mathrm{ng} / \mathrm{mL})$ and GTS-21 $(100 \mu \mathrm{M})$ for 4 hours. Data are represented as mean $\pm \mathrm{SEM}$ fold expression of the gene of interest relative to control (expression in monocytes incubated with medium alone). Data from 5 different donors, three independent experiments are shown. \# indicates $\mathrm{p}<0.05$ compared to medium, * indicates $p<0.05$ compared to LPS (paired Student's t-test).

\section{Figure 7}

Effect of the JAK2 inhibitor AG490 $(100 \mu \mathrm{M})$ on TNF- $\alpha$ production in human PBMCs stimulated with LPS $(1 \mathrm{ng} / \mathrm{mL})$, GTS-21 $(10$ and $100 \mu \mathrm{M})$ and nicotine $(1 \mathrm{mM})$ for 22 hours. Data are represented as mean \pm SEM (5-7 different donors, two independent experiments). * indicates $\mathrm{p}<0.05$ compared to LPS, \# indicates $\mathrm{p}<0.05$ compared to TNF$\alpha$ response with the same (concentration of) nicotinic agonist in the absence of AG490 (paired Student's t-test). 
Table 1: up/down regulation of JAK-STAT related genes compared to RPMI. Only genes which are significantly and more than twofold up/downregulated are shown

\begin{tabular}{|c|c|c|c|c|c|}
\hline \multirow{2}{*}{$\frac{\text { GTS-21 }}{\text { SOCS2 }}$} & \multicolumn{3}{|c|}{ LPS } & \multicolumn{2}{|c|}{ LPS+GTS-21 } \\
\hline & 8,30 & IL2RA & 176,11 & IL2RA & 376,84 \\
\hline INSR & 3,11 & SOCS1 & 48,56 & STAT4 & 34,75 \\
\hline EPOR & 2,55 & ISG15 & 35,88 & SOCS1 & 24,44 \\
\hline OSM & 2,36 & CXCL9 & 24,82 & ISG15 & 16,12 \\
\hline PRLR & 2,28 & GBP1 & 18,96 & SOCS3 & 12,92 \\
\hline SMAD1 & 2,24 & SOCS2 & 18,69 & GBP1 & 9,01 \\
\hline IRF9 & $-2,32$ & SOCS3 & 17,31 & NFKB1 & 3,22 \\
\hline IRF1 & $-2,50$ & STAT4 & 17,29 & STAT5A & 3,03 \\
\hline GBP1 & $-2,68$ & IL20 & 8,52 & SMAD1 & 2,75 \\
\hline $\mathrm{A} 2 \mathrm{M}$ & $-2,90$ & IFNG & 6,53 & STAT2 & 2,58 \\
\hline ISG15 & $-2,97$ & OAS1 & 5,34 & STAT1 & 2,45 \\
\hline GATA3 & $-3,30$ & STAT1 & 4,70 & IL4R & 2,30 \\
\hline CCND1 & $-3,38$ & NFKB1 & 3,09 & PTPN1 & 2,11 \\
\hline IFNAR1 & $-4,05$ & STAT2 & 3,04 & STAT3 & 2,09 \\
\hline OAS1 & $-4,99$ & NR3C1 & 2,35 & FCGR1A & $-2,25$ \\
\hline MYC & $-10,96$ & CDKN1A & 2,29 & SMAD2 & $-2,26$ \\
\hline & & IL6ST & 2,14 & TYK2 & $-2,33$ \\
\hline & & TYK2 & $-2,38$ & USF1 & $-2,66$ \\
\hline & & USF1 & $-2,38$ & IFNGR1 & $-3,08$ \\
\hline & & STAT5B & $-2,45$ & EGFR & -3.67 \\
\hline & & SMAD3 & $-2,52$ & SMAD3 & $-3,92$ \\
\hline & & IFNGR1 & $-2,94$ & HMGA1 & $-4,39$ \\
\hline & & SH2B1 & $-2,95$ & FCER1A & $-4,75$ \\
\hline & & SOCS5 & $-2,97$ & NOS2A & $-4,92$ \\
\hline & & NOS2A & $-4,15$ & MYC & $-5,43$ \\
\hline & & $\mathrm{F} 2$ & $-5,22$ & SIT1 & $-7,36$ \\
\hline & & FCER1A & $-5,43$ & $\mathrm{~A} 2 \mathrm{M}$ & $-8,83$ \\
\hline & & EPOR & $-5,48$ & CSF1R & $-13,08$ \\
\hline & & CSF1R & $-8,46$ & & \\
\hline & & INSR & $-9,77$ & & \\
\hline & & SMAD5 & $-30,56$ & & \\
\hline
\end{tabular}


Figure 1
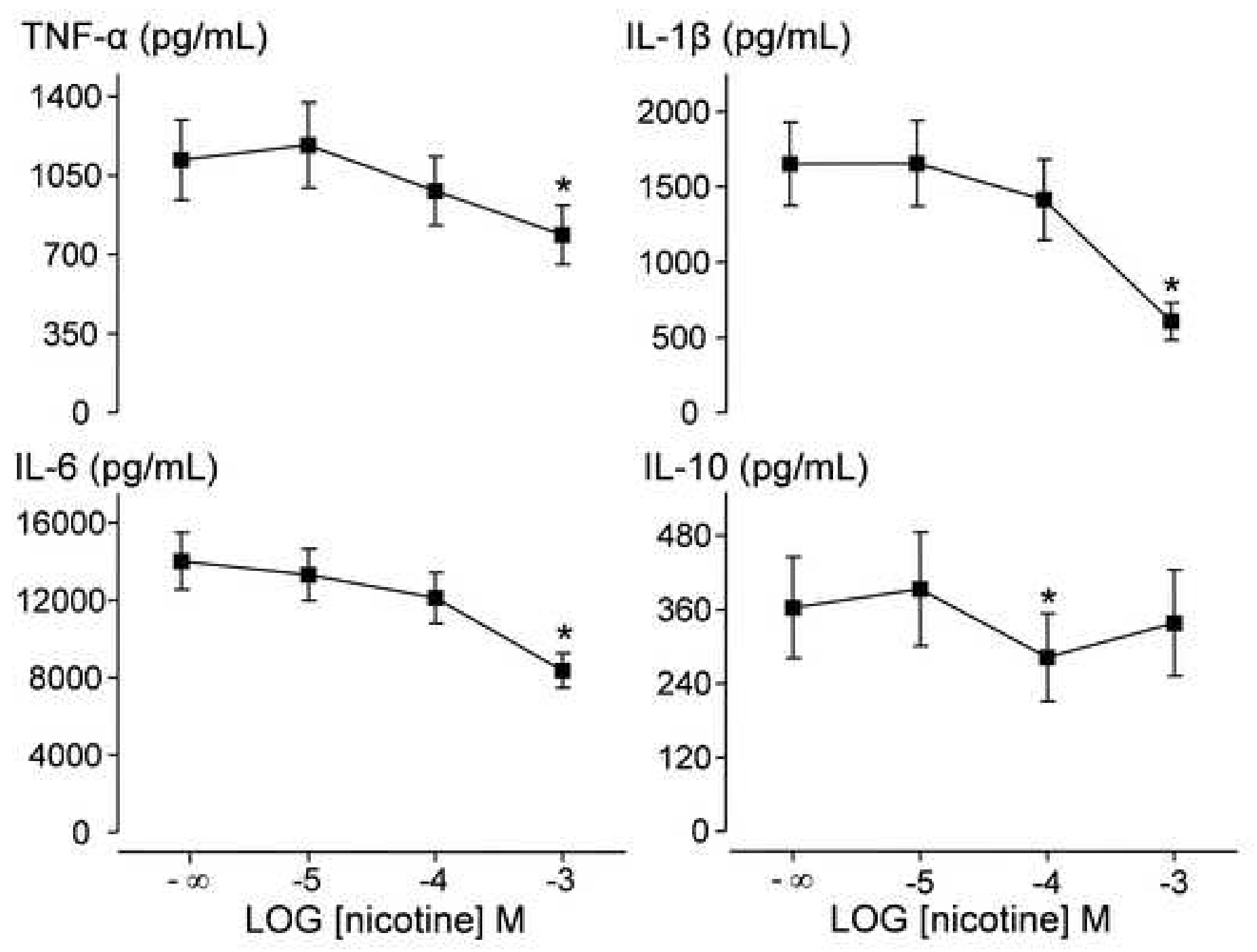
Figure 2

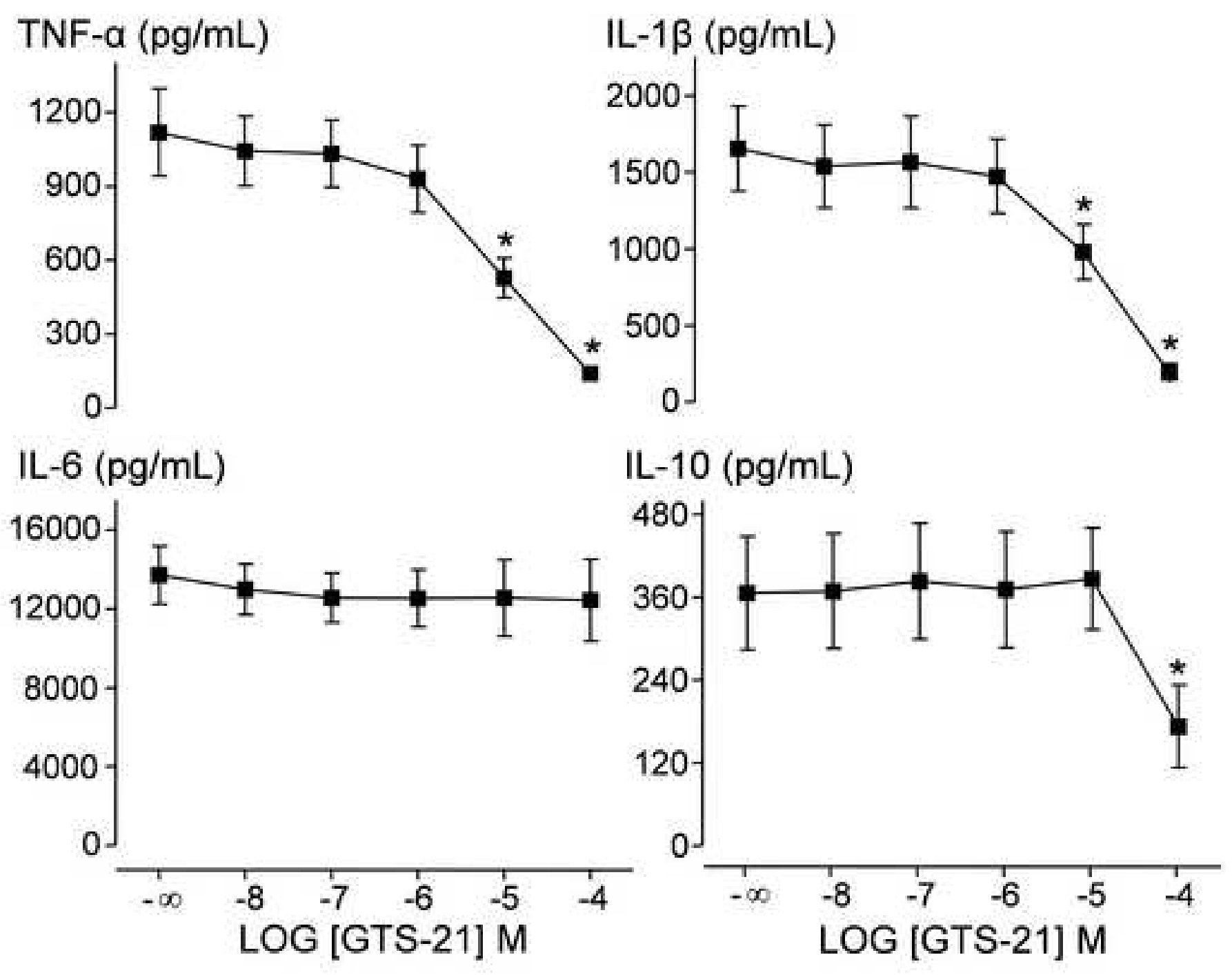


Figure 3

A

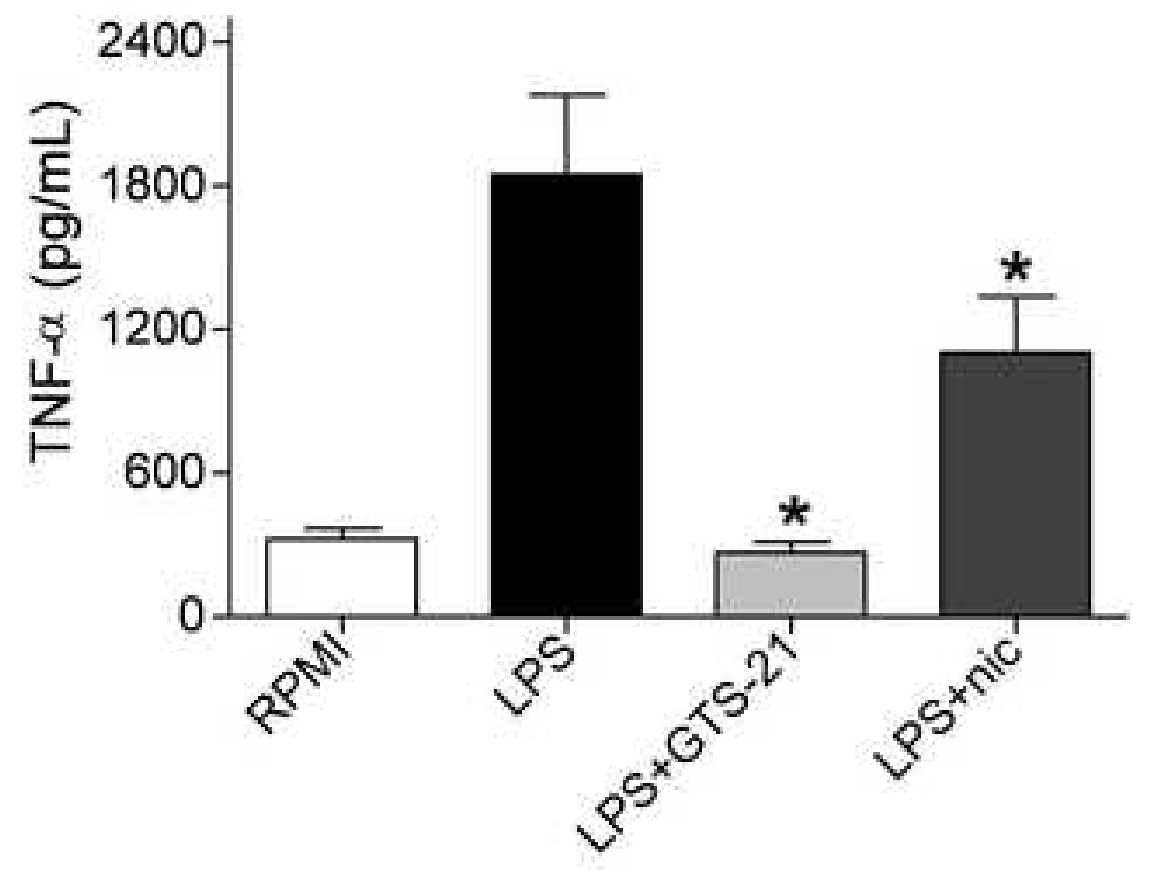

B

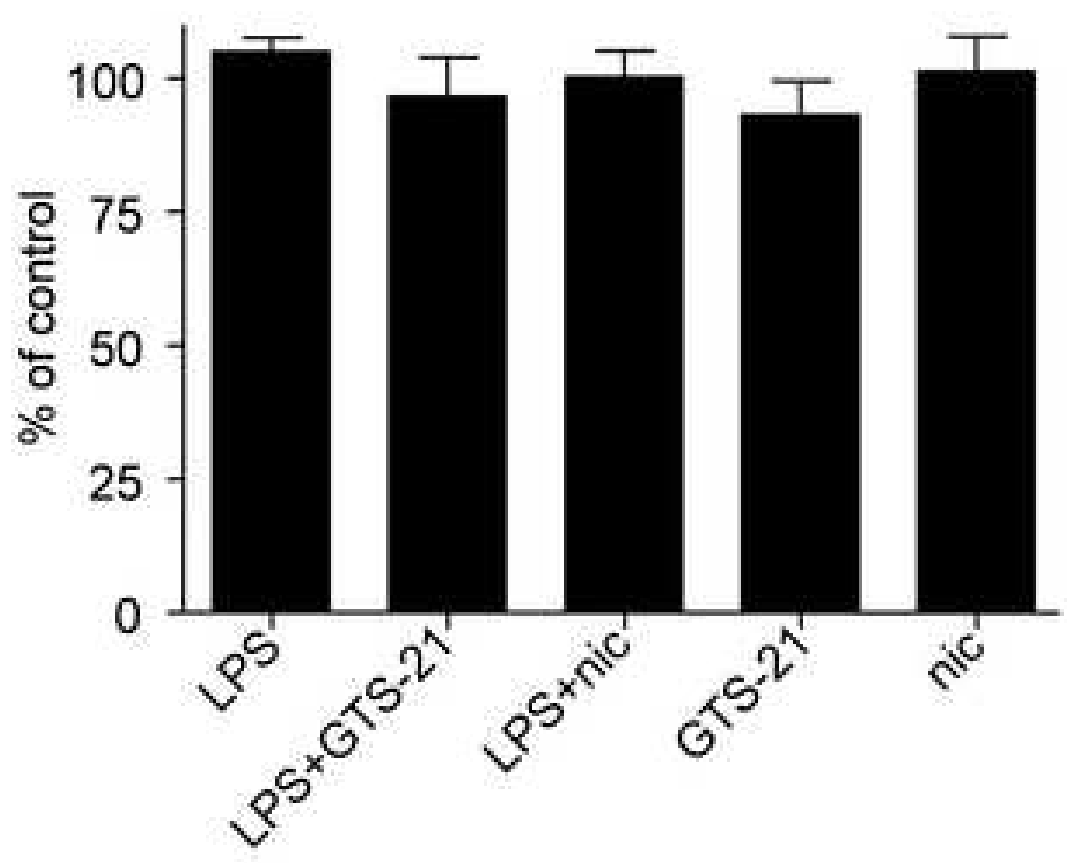


Figure 4

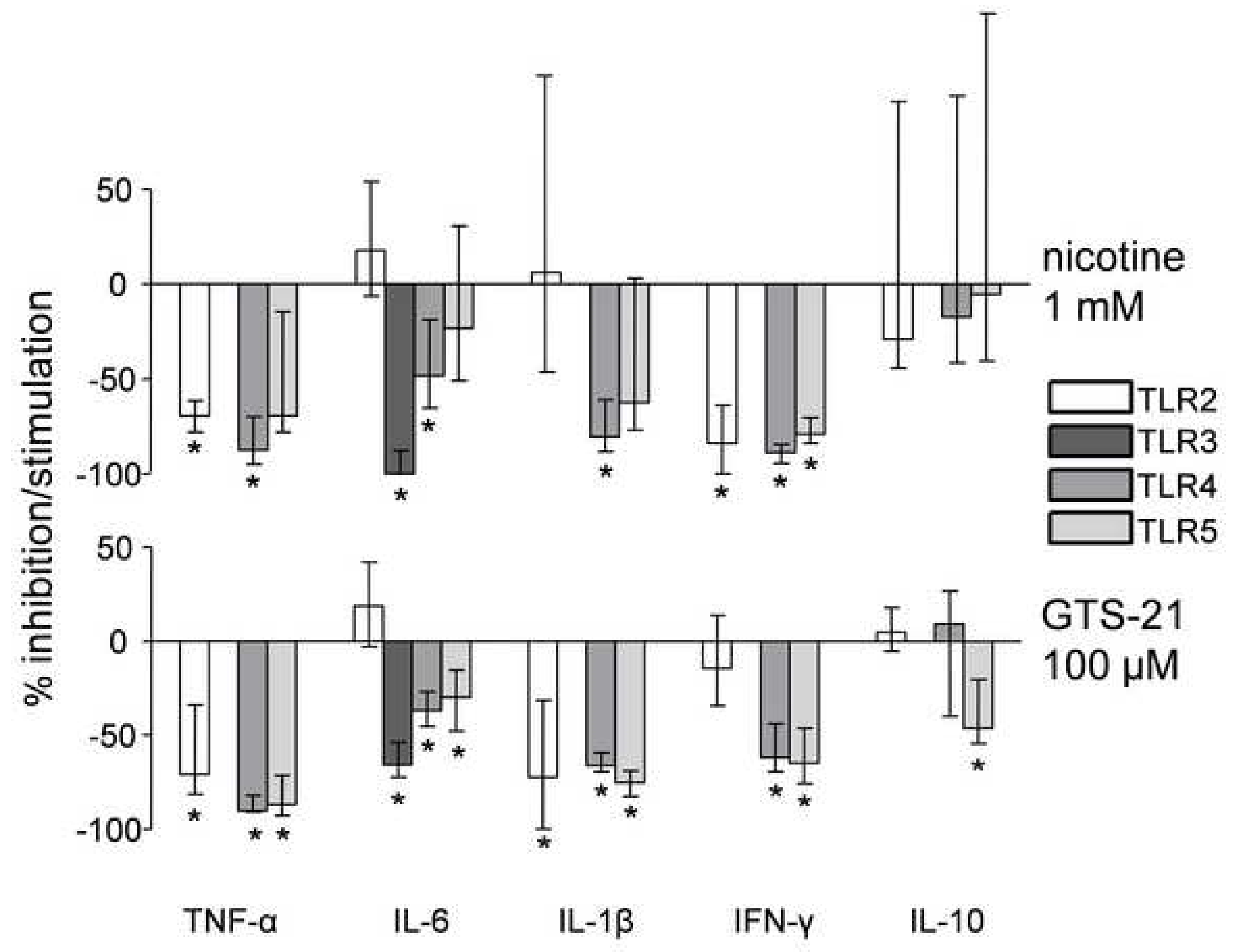


Figure 5
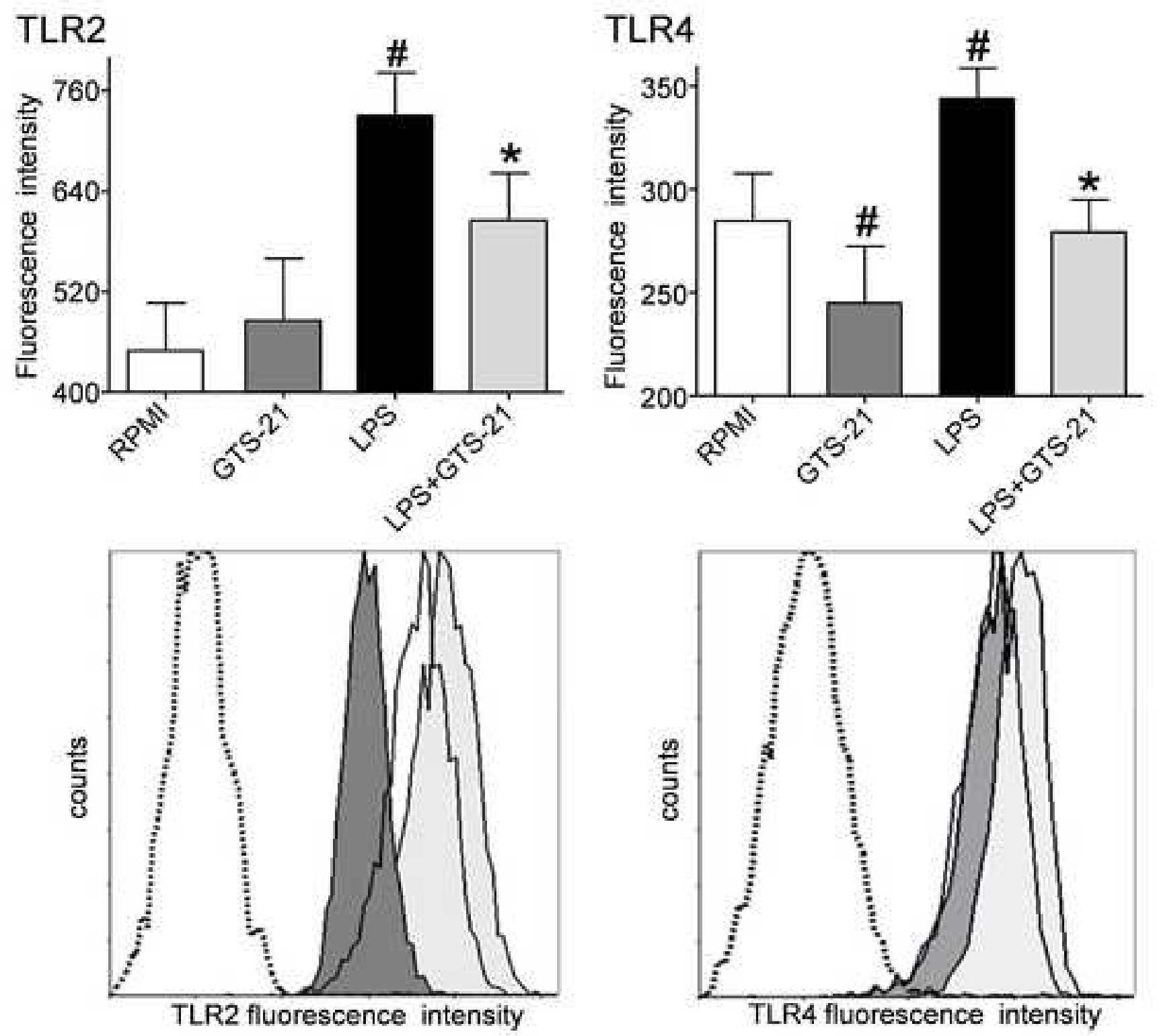

rage 44 or 4 / 
Figure 6
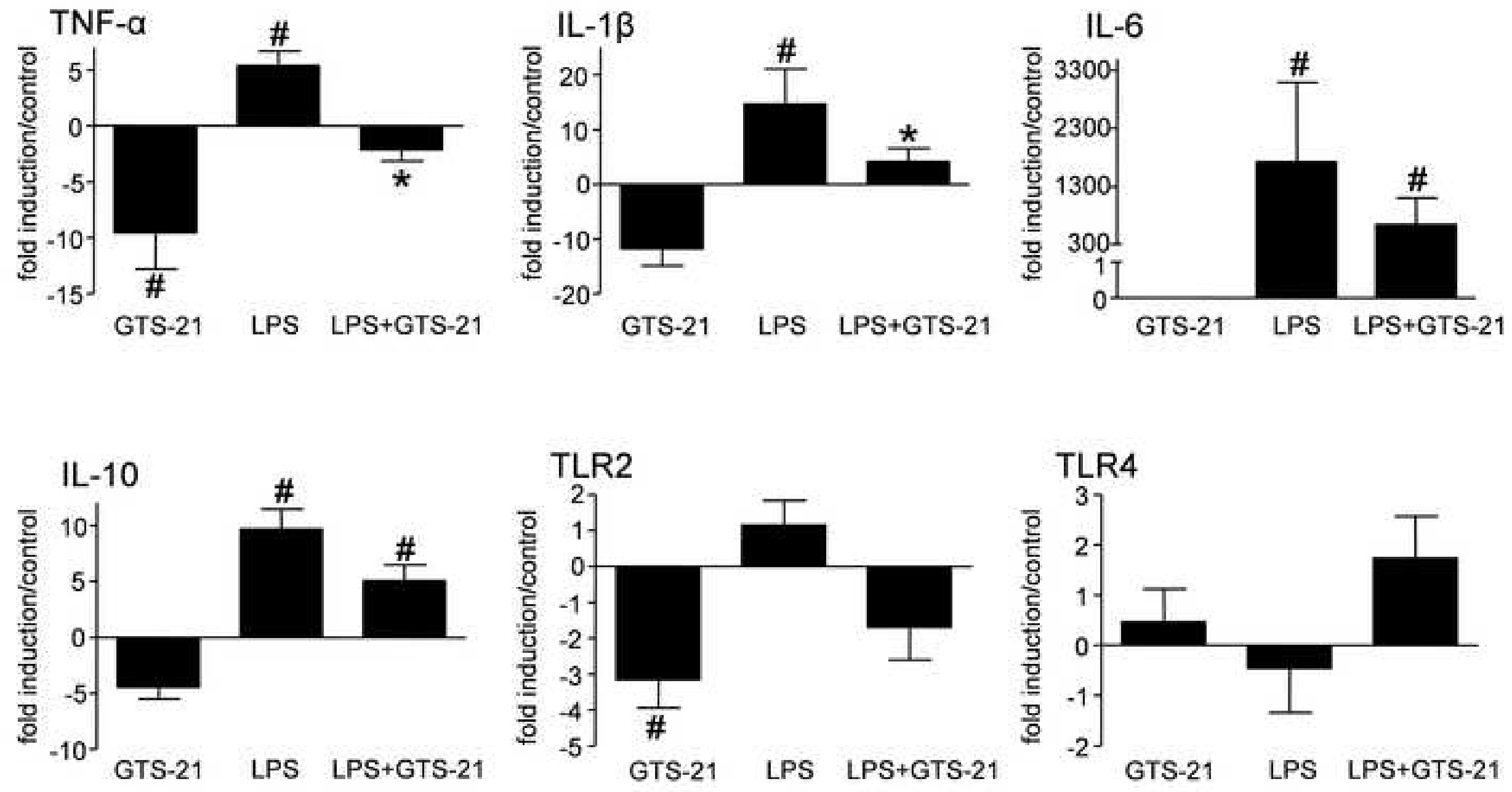
Figure 7

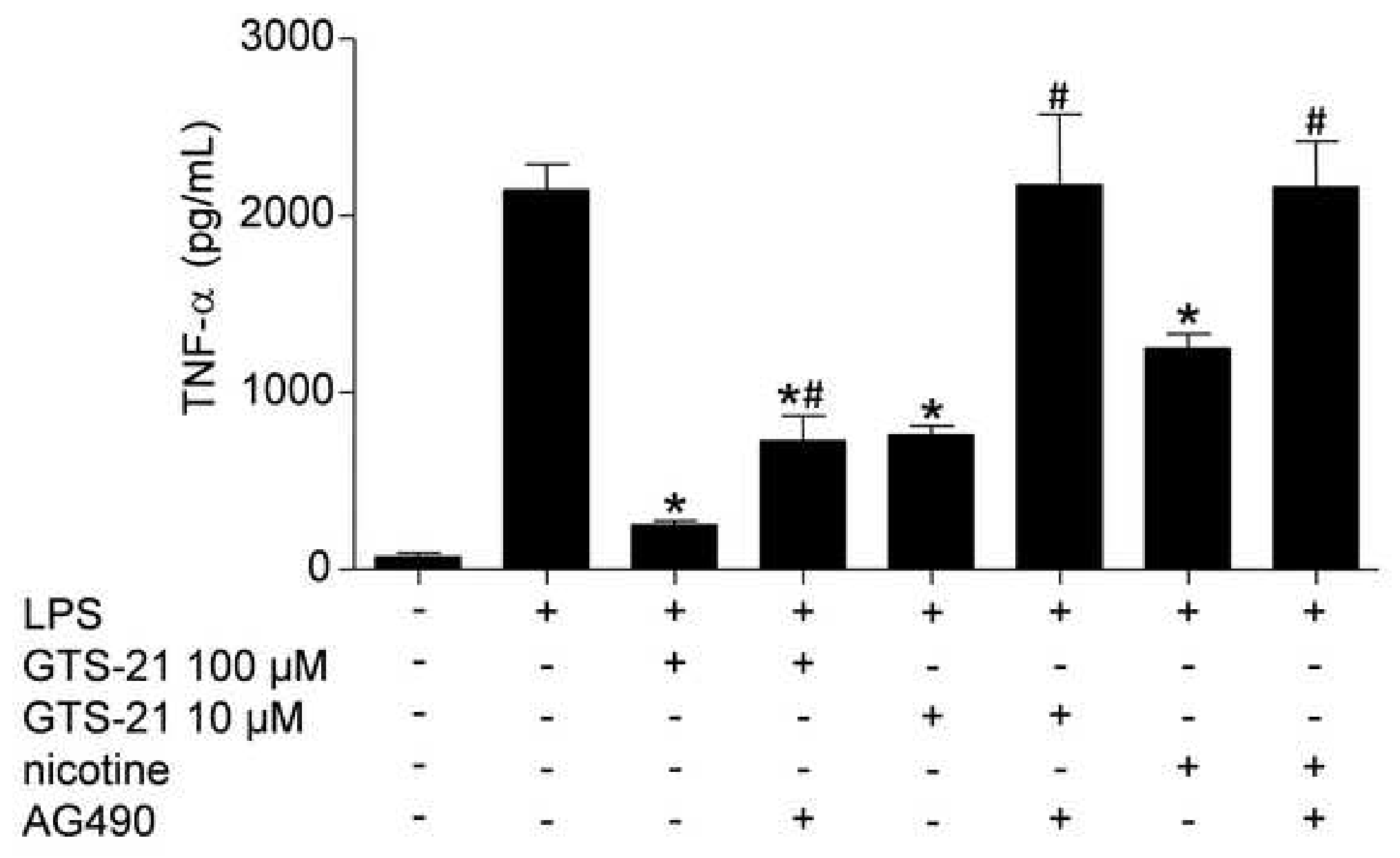


